\title{
Ocular Manifestations of Rheumatoid Arthritis and Complications of Hydroxychloroquine Treatment
}

Zeinab Sayed Hasan, Sanaa Ahmed Mohamed, Fatma Essam Abdelmohsen*

Department of Ophthalmology, Faculty of Medicine, Al-Azhar University, Cairo, Egypt

Corresponding author: Fatma Essam Abdelmohsen, Mobile: (+20)01127521596, E-mail:dr.fatma.esam@gmail.com

\begin{abstract}
Background: Rheumatoid arthritis (RA) is the most common autoimmune disease. Ocular manifestations of RA vary and are mainly keratoconjunctivitis sicca, episcleritis, scleritis and keratitis. Antimalarial drugs [hydroxychloroquine (HCQ) and chloroquine (CQ)] have been used for the treatment of RA.

Objective: The aim of this study was to study the ocular manifestations of rheumatoid arthritis and the complications of the use of hydroxychloroquine in treatment.

Patients and methods: A prospective study that was conducted at Al-Zahraa University Hospital. The study included a total of 80 eyes of 40 patients. Patients were divided into two groups: Group (1) 20 RA patients not using HCQ treatment and group (2) 20 RA patients using HCQ treatment. All patients underwent complete ophthalmic examination including SD-OCT. Results: the most ocular manifestations found in patients were keratoconjunctivitis sicca (KCS) $93.8 \%$, scleritis and episcleritis $2.5 \%$, acute anterior uveitis (AAU) and sclerosing keratitis $1.3 \%$. Regarding SD-OCT finding comparing between the two groups, we found signs of early HCQ retinopathy in patients of group 2 in the form of parafoveal and perifoveal thining compared to group 1.

Conclusion: RA is associated with many extra-articular manifestations, HCQ and CQ used in treatment of RA have significant efficacy and safety, but with long duration of using can cause retinopathy, and follow up of patients is necessary to detect early retinopathy.
\end{abstract}

Keywords: Rheumatoid arthritis, ocular manifestations, hydroxychloroquine, retinopathy.

\section{INTRODUCTION}

Rheumatoid arthritis (RA) is one of the common autoimmune disease, which causes chronic inflammation of the joints and other areas of the body, the exact etiopathogenesis of RA is yet unknown ${ }^{\left({ }^{(1)}\right.}$. The prevalence of RA worldwide is around $0.8 \%$, extra-articular manifestation in RA are present in 10$20 \%$ of patients, which are more frequent in seropositive patients ${ }^{(2)}$. Ocular manifestations of RA include KCS, episcleritis, scleritis, keratitis, glaucoma and retinal vasculitis. Ocular manifestations occur independently or in association with a disease exacerbation. They occur in $25 \%$ of patients with RA (3).

HCQ is a drug increasingly used in the treatment of systemic lupus erythematosus, rheumatoid arthritis and other autoimmune disorders. Long-term use of HCQ can cause retinopathy, a condition in which harmful effects on the retina can lead to permanent loss of vision affecting both eyes ${ }^{(4)}$. Specialised retinal tests are able to detect early evidence of retinopathy before a patient notices visual changes. Looking for a particular condition in a person thought to be at risk, in order to detect it before symptoms develop to minimise the risk of harm is a process called "screening". The aim of screening for HCQ retinopathy is to detect the earliest definite signs of the condition ${ }^{(5)}$.

Although most patients taking HCQ will not develop retinopathy, around $7.5 \%$ of individuals taking HCQ for more than 5 years may have signs of retinal damage detected on specialised tests. It is recognised that most hospital eye services have modern retinal imaging technology (optical coherence tomography and fundus autofluorescence) and automated visual field testing, which make local screening possible. Such tests are generally acceptable to patients ${ }^{(\mathbf{6})}$.

\section{AIM OF THE WORK}

The aim of this study was to study the ocular manifestations of rheumatoid arthritis and the complications of hydroxychloroquine treatment.

\section{PATIENTS AND METHODS}

A total of 80 eyes of 40 patients were enrolled in our study, which was conducted in Ophthalmology Department, Al-Zahraa University Hospital from December 2018 till June 2019. Patients were selected from Al-Zahraa Rheumatology Outpatient Clinics. Patients were divided into two equal groups: group (1) that included 20 RA patients not using HCQ drug and group (2) that included $20 \mathrm{RA}$ patients using HCQ drug.

Ethical consideration and written informed consent:

An approval of the study was obtained from AlAzhar University Academic and Ethical Committee. All patients signed an informed written consent for acceptance of the examinations.

\section{Methods:}

All patients will be subjected to the following:

1. Detailed history taking (age, gender, treatment, etc...)

2. Complete ocular examination including uncorrected visual acuity (UCVA) and best corrected visual acuity (BCVA) using Snellen chart.

3. Slit-lamp examination for the anterior segment. 
4. IOP measurement using Goldman applanation tonometer.

5. Indirect and direct ophthalmoscopy.

6. Schirmer test and break up time test.

7. SD-OCT scans with OCT-RTVue XR Avanti system (Optovue Inc. Fremont, USA) was used to measure central foveal, perifoveal and parafoveal thickness and IS/OS line integrity.

\section{Inclusion criteria:}

Patients diagnosed with RA within 5 years and for more than 5 years, 20 of them taking HCQ and 20 not taking HCQ treatment.

\section{Exclusion criteria:}

1. History of previous laser, previous ocular surgeries (except for uncomplicated cataract surgery) or ocular trauma.

2. Insufficient media clarity.

3. Diabetes mellitus or decompensated heart failure.

4. Age-related macular degeneration, myopic atrophy, optic neuropathy, or amblyopia.

5. Glaucoma patients.

\section{Statistical analysis:}

Data were collected, revised, coded and entered to the Statistical Package for Social Science (IBM SPSS) version 23. The quantitative data were presented as mean, standard deviations and ranges when parametric. Also qualitative variables were presented as number and percentages.

The comparison between groups regarding qualitative data was done by using Chi-square test and/or Fisher exact test when the expected count in any cell found less than 5 .

The comparison between two independent groups with quantitative data and parametric distribution was done by using independent t-test while the comparison between more than two independent groups with quantitative data and parametric distribution were done by using One Way ANOVA.

The confidence interval was set to $95 \%$ and the margin of error accepted was set to $5 \%$. So, the p-value was considered significant as the following:

- $\quad$ P-value > 0.05: Non significant (NS)

- $\quad$ P-value < 0.05: Significant $(\mathrm{S})$

- P-value < 0.01: Highly significant (HS)

\section{RESULTS}

After a short-term study of 6 months, the following observations were obtained:

Table (1): Ocular symptoms in both groups

\begin{tabular}{|l|c|}
\hline & No. $(\%)$ \\
\hline KCS & $75(93.8 \%)$ \\
\hline Episcleritis & $2(2.5 \%)$ \\
\hline AAU & $1(1.3 \%)$ \\
\hline PEE & $2(2.5 \%)$ \\
\hline Anterior nodular scleritis & $2(2.5 \%)$ \\
\hline Pterygium & $1(1.3 \%)$ \\
\hline Sclerosing keratitis & $1(1.3 \%)$ \\
\hline PSC & $5(6.3 \%)$ \\
\hline IMSC & $19(23.8 \%)$ \\
\hline Total & $80(100.0 \%)$ \\
\hline
\end{tabular}

The most ocular symptoms found in patients were $\mathrm{KCS}$, episcleritis, scleritis and AAU. Also, punctuate epithelial erosion (PEE) and sclerosing keratitis as complications of dry eye. In addition, some patients had posterior subcapsular cataract (PSC), which affected their vision and others had immature senile cataract (Table 1).

Table (2): Comparison between the two studied groups regarding demographic data

\begin{tabular}{|c|c|c|c|c|c|c|}
\hline & Group I & Group II & \multirow{2}{*}{ Test value } & \multirow{2}{*}{ P-value } & \multirow{2}{*}{ Sig. } \\
\hline & & No. $=20$ & No. $=20$ & & & \\
\hline Age (years) & $\begin{array}{l}\text { Mean } \pm \text { SD } \\
\text { Range }\end{array}$ & $\begin{array}{c}48.55 \pm 11.20 \\
25-70\end{array}$ & $\begin{array}{c}33.65 \pm 11.04 \\
36-71\end{array}$ & $-1.451 \bullet$ & 0.155 & NS \\
\hline Sex & $\begin{array}{l}\text { Females } \\
\text { Males }\end{array}$ & $\begin{array}{c}20(100.0 \%) \\
0(0.0 \%)\end{array}$ & $\begin{array}{c}19(95.0 \%) \\
1(5.0 \%)\end{array}$ & $1.026^{*}$ & 0.311 & NS \\
\hline Disease duration (years) & \begin{tabular}{|l} 
Mean \pm SD \\
Range
\end{tabular} & $\begin{array}{c}11.50 \pm 5.53 \\
4-25\end{array}$ & $\begin{array}{c}12.35 \pm 8.03 \\
1-32 \\
\end{array}$ & $-0.551 \bullet$ & 0.583 & NS \\
\hline $\begin{array}{l}\text { Duration of HCQ treatment } \\
\text { (years) }\end{array}$ & \begin{tabular}{|l} 
Mean \pm SD \\
Range
\end{tabular} & & $\begin{array}{c}8.05 \pm 4.77 \\
1-18 \\
\end{array}$ & & & \\
\hline UCVA & $\begin{array}{l}\text { Mean } \pm \text { SD } \\
\text { Range }\end{array}$ & $\begin{array}{l}0.40 \pm 0.23 \\
0-1\end{array}$ & $\begin{array}{c}0.66 \pm 0.28 \\
0.2-1.3\end{array}$ & $-4.517 \bullet$ & 0.000 & HS \\
\hline BCVA & $\begin{array}{l}\text { Mean } \pm \text { SD } \\
\text { Range }\end{array}$ & $\begin{array}{l}0.16 \pm 0.14 \\
0-0.6\end{array}$ & $\begin{array}{c}0.31 \pm 0.22 \\
0-1\end{array}$ & $-3.570 \bullet$ & 0.001 & HS \\
\hline IOP & $\begin{array}{l}\text { Mean } \pm \text { SD } \\
\text { Range }\end{array}$ & $\begin{array}{c}14.58 \pm 1.01 \\
12-16\end{array}$ & $\begin{array}{c}15.08 \pm 1.05 \\
14-18\end{array}$ & $-2.174 \bullet$ & 0.033 & $\mathrm{~S}$ \\
\hline IS/OS junction & \begin{tabular}{|l|} 
Interrupted \\
Intact
\end{tabular} & $\begin{array}{l}2(10.0 \%) \\
18(90.0 \%)\end{array}$ & \begin{tabular}{|l|}
$4(20.0 \%)$ \\
$16(80.0 \%)$ \\
\end{tabular} & 0.784 & 0.375 & NS \\
\hline
\end{tabular}

Independent t-test; *: Chi-square test $\mathrm{P}>0.05$ : Non significant; $\mathrm{P}<0.05$ : Significant; $\mathrm{P}<0.01$ : Highly significant,

Table (2) showed that there was no statistically significant difference found between the two studied groups regarding age, sex, disease duration and IS/OS junction, while there was statistically significant difference between them regarding UCVA, BCVA and IOP. 


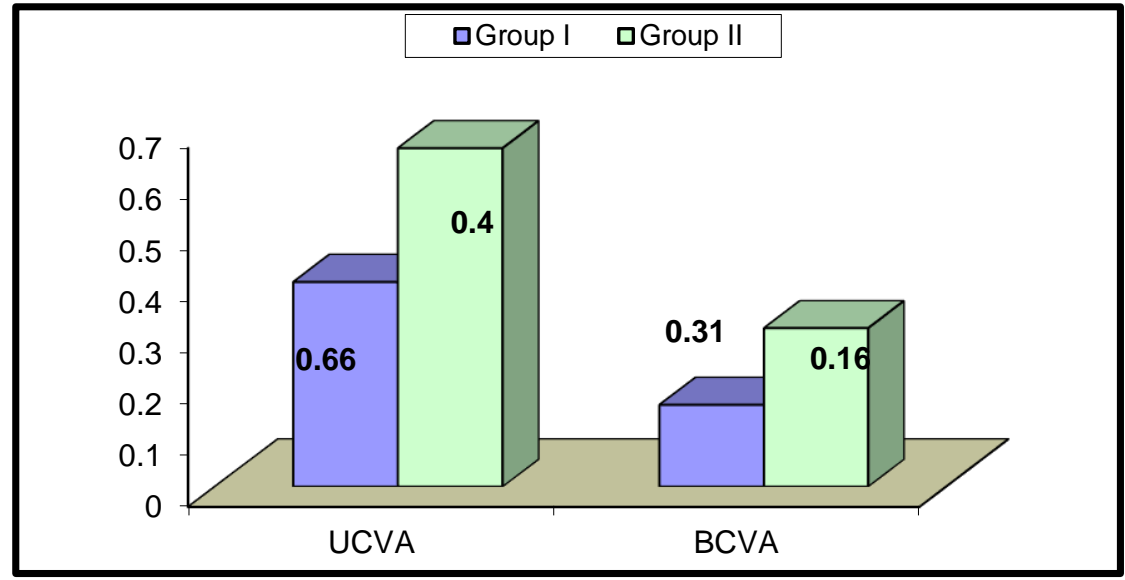

Figure (1): Bar chart between groups according to LOG MAR UCVA and BCVA

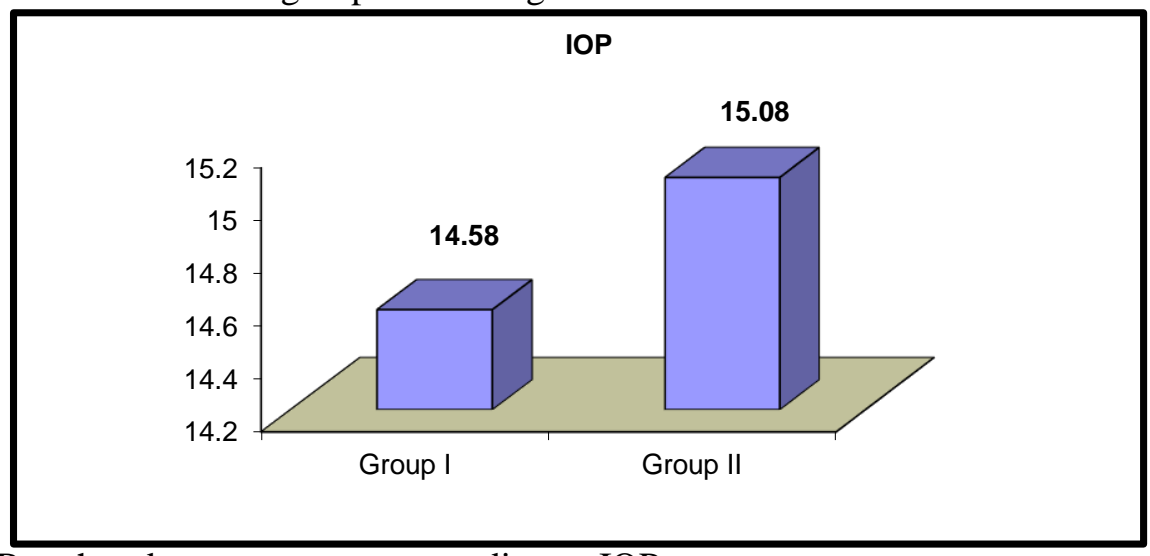

Figure (2): Bar chart between groups according to IOP

We found decrease in vision and increase in IOP in group (2) as complications of HCQ treatment (Figure 1, 2).

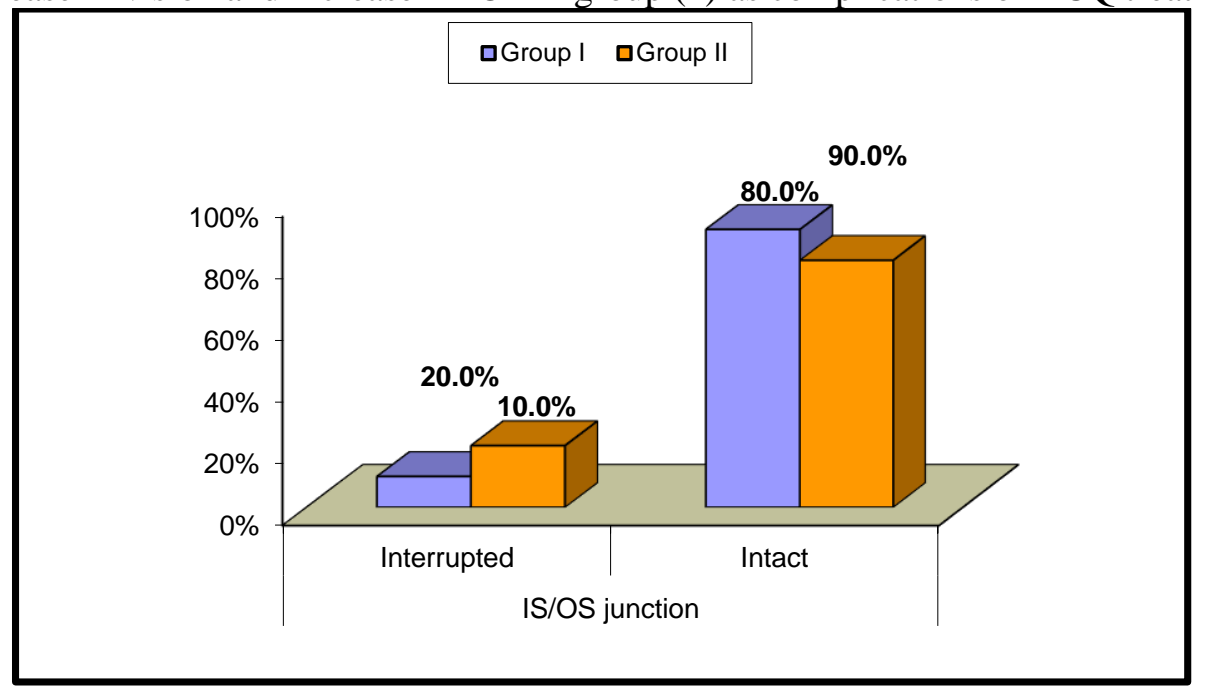

Figure (3): Bar chart between groups according to IS/OS junction. According to IS/OS junction we found 4 cases in group (2) and 2 cases in group (1) had interrupted IS/OS junction with no statistically significant difference between both groups (Figure3).

Table (3): Comparison between the two studied groups regarding Schirmer's test, break up time test and central foveal thickness

\begin{tabular}{|c|c|c|c|c|c|c|}
\hline & Group I & Group II & \multirow{2}{*}{ Test value• } & \multirow{2}{*}{ P-value } & \multirow{2}{*}{ Sig. } \\
\hline & & No. $=20$ & No. $=20$ & & & \\
\hline Schirmer's test & $\begin{array}{l}\text { Mean } \pm \text { SD } \\
\text { Range }\end{array}$ & $\begin{array}{c}6.18 \pm 3.55 \\
2-15\end{array}$ & $\begin{array}{c}5.15 \pm 2.38 \\
2-14\end{array}$ & 2.299 & 0.133 & NS \\
\hline Break up time test & $\begin{array}{l}\text { Mean } \pm \mathrm{SD} \\
\text { Range }\end{array}$ & $\begin{array}{c}6.23 \pm 2.45 \\
3-11\end{array}$ & $\begin{array}{c}5.85 \pm 1.98 \\
3-10\end{array}$ & 0.565 & 0.454 & NS \\
\hline Central foveal thickness & $\begin{array}{l}\text { Mean } \pm \mathrm{SD} \\
\text { Range }\end{array}$ & $\begin{array}{c}240.18 \pm 14.72 \\
218-291\end{array}$ & $\begin{array}{c}237.95 \pm 30.70 \\
129-302\end{array}$ & 0.413 & 0.681 & NS \\
\hline
\end{tabular}

•: One Way ANOVA, Table (3) showed that there was no statistically significant difference between the two studied groups regarding Schirmer test, break up time test and central foveal thickness (CFT). As the most ocular symptom in 
RA patients is KCS, so we tested patients by Schirmer test and break up time test, we found that most of our patients had sever and moderate dry eye in both groups with no statistically significant difference as shown in table (3).

Table (4): Comparison between the two studied groups regarding parafoveal thickness

\begin{tabular}{|c|c|c|c|c|c|c|}
\hline \multicolumn{2}{|c|}{ Parafoveal thickness } & Group I & Group II & \multirow{2}{*}{$\begin{array}{c}\text { Test value• } \\
36.206\end{array}$} & \multirow{2}{*}{$\begin{array}{c}\text { P-value } \\
0.000\end{array}$} & \multirow{2}{*}{$\begin{array}{l}\text { Sig. } \\
\text { HS }\end{array}$} \\
\hline Superior quadrant & $\begin{array}{l}\text { Mean } \pm \text { SD } \\
\text { Range }\end{array}$ & $\begin{array}{c}317.03 \pm 14.13 \\
260-339\end{array}$ & $\begin{array}{c}289.30 \pm 25.49 \\
215-337\end{array}$ & & & \\
\hline Inferior quadrant & $\begin{array}{l}\text { Mean } \pm \text { SD } \\
\text { Range }\end{array}$ & $\begin{array}{c}313.25 \pm 13.07 \\
280-338\end{array}$ & $\begin{array}{c}287.15 \pm 33.20 \\
131-336\end{array}$ & 21.399 & 0.000 & HS \\
\hline Nasal quadrant & $\begin{array}{l}\text { Mean } \pm \text { SD } \\
\text { Range }\end{array}$ & $\begin{array}{c}315.68 \pm 14.26 \\
270-346\end{array}$ & $\begin{array}{c}290.23 \pm 24.01 \\
230-343\end{array}$ & 33.218 & 0.000 & HS \\
\hline Temporal quadrant & $\begin{array}{l}\text { Mean } \pm \text { SD } \\
\text { Range }\end{array}$ & $\begin{array}{c}302.25 \pm 13.92 \\
263-330\end{array}$ & $\begin{array}{c}280.00 \pm 16.41 \\
232-313\end{array}$ & 42.759 & 0.000 & HS \\
\hline
\end{tabular}

$\because$ One Way ANOVA

Table (4) showed that there was highly statistically significant difference between the two studied groups regarding parafoveal thickness in all quadrants. According to SD-OCT finding, we used SD-OCT to measure central foveal, parafoveal and perifoveal thickness to evaluate complications of HCQ. We found signs of early retinopathy in patients of group (2) in the form of thinning in parafoveal and perifoveal region with statistically significant difference compared to group (1) as shown in table (4) \& (5). There was thinning in CFT but with no statistically significant difference between both groups as shown in table (3).

Table (5): Comparison between the two studied groups regarding perifoveal thickness

\begin{tabular}{|c|c|c|c|c|c|c|}
\hline \multicolumn{2}{|c|}{ Perifoveal thickness } & Group I & Group II & \multirow{2}{*}{$\begin{array}{c}\text { Test value• } \\
29.894\end{array}$} & \multirow{2}{*}{$\frac{P \text {-value }}{0.000}$} & \multirow{2}{*}{$\begin{array}{r}\text { Sig } \\
\text { HS }\end{array}$} \\
\hline Superior quadrant & $\begin{array}{l}\text { Mean } \pm \text { SD } \\
\text { Range }\end{array}$ & $\begin{array}{c}289.18 \pm 22.56 \\
265-388\end{array}$ & $\begin{array}{c}264.10 \pm 18.23 \\
223-310\end{array}$ & & & \\
\hline Inferior quadrant & $\begin{array}{l}\text { Mean } \pm \text { SD } \\
\text { Range }\end{array}$ & $\begin{array}{c}278.30 \pm 20.40 \\
260-390\end{array}$ & $\begin{array}{c}249.93 \pm 25.95 \\
142-301\end{array}$ & 29.562 & 0.000 & HS \\
\hline Nasal quadrant & $\begin{array}{l}\text { Mean } \pm \text { SD } \\
\text { Range }\end{array}$ & $\begin{array}{c}297.10 \pm 9.44 \\
276-313\end{array}$ & $\begin{array}{c}272.98 \pm 29.72 \\
164-328\end{array}$ & 23.934 & 0.000 & HS \\
\hline Temporal quadrant & $\begin{array}{l}\text { Mean } \pm \text { SD } \\
\text { Range }\end{array}$ & $\begin{array}{c}277.83 \pm 13.02 \\
255-324\end{array}$ & $\begin{array}{c}253.58 \pm 22.97 \\
192-301\end{array}$ & 33.738 & 0.000 & HS \\
\hline
\end{tabular}

$\because$ One Way ANOVA

Table (5) showed that there was highly statistically significant difference between the two studied groups regarding perifoveal thickness in all quadrants.

Table (6): Relation between duration of HCQ treatment and parafoveal thickness

\begin{tabular}{|c|c|c|c|c|c|c|c|}
\hline \multirow{2}{*}{\multicolumn{2}{|c|}{$\begin{array}{l}\text { Parafoveal } \\
\text { thickness }\end{array}$}} & \multicolumn{3}{|c|}{ Duration of HCQ treatment (years) } & \multirow{3}{*}{$\begin{array}{c}\begin{array}{c}\text { Test } \\
\text { value• }\end{array} \\
4.003\end{array}$} & \multirow{3}{*}{$\begin{array}{c}\text { P-value } \\
0.027\end{array}$} & \multirow{3}{*}{$\begin{array}{c}\text { Sig. } \\
S\end{array}$} \\
\hline & & $<5$ years & 5-10 years & $>10$ years & & & \\
\hline Superior quadrant & $\begin{array}{l}\text { Mean } \pm \text { SD } \\
\text { Range }\end{array}$ & $\begin{array}{c}300.94 \pm 16.53 \\
271-337\end{array}$ & $\begin{array}{c}281.70 \pm 25.90 \\
215-311\end{array}$ & $\begin{array}{c}278.17 \pm 30.37 \\
240-335\end{array}$ & & & \\
\hline Inferior quadrant & $\begin{array}{l}\text { Mean } \pm \text { SD } \\
\text { Range }\end{array}$ & $\begin{array}{c}303.17 \pm 16.95 \\
272-336\end{array}$ & $\begin{array}{c}277.30 \pm 53.39 \\
131-320 \\
\end{array}$ & $\begin{array}{c}271.33 \pm 18.76 \\
250-302\end{array}$ & 4.618 & 0.016 & S \\
\hline Nasal quadrant & $\begin{array}{l}\text { Mean } \pm \text { SD } \\
\text { Range }\end{array}$ & $\begin{array}{c}302.56 \pm 15.05 \\
268-334\end{array}$ & $\begin{array}{c}284.20 \pm 22.04 \\
234-319\end{array}$ & $\begin{array}{c}276.75 \pm 28.59 \\
230-343\end{array}$ & 5.674 & 0.007 & HS \\
\hline Temporal quadrant & $\begin{array}{l}\text { Mean } \pm \text { SD } \\
\text { ange }\end{array}$ & $\begin{array}{c}290.00 \pm 13.63 \\
260-313\end{array}$ & $\begin{array}{c}276.10 \pm 12.12 \\
251-291\end{array}$ & $\begin{array}{c}268.25 \pm 14.81 \\
232-288\end{array}$ & 9.683 & 0.000 & $\mathrm{HS}$ \\
\hline
\end{tabular}

$\bullet$ One Way ANOVA

Table (6) showed that there was statistically significant difference concerning duration of HCQ treatment regarding parafoveal thickness in superior and inferior quadrant and highly statistically significant difference in nasal and temporal quadrant. As occurrence of HCQ retinopathy depend mainly on cumulative dose and our patients were taking the same daily dose of HCQ, they differed only in duration of taking HCQ so we divided patients in group (2) according to duration of HCQ to less than 5 years, from 5 to 10 years and more than 10 years. Then we compared between them regarding central foveal, parafoveal and perifoveal thickness. We found that with increasing the duration of HCQ, there was more thinning in parafoveal and perifoveal regions with statistically significant difference as shown in table (6). 
Table (7): Relation between duration of HCQ treatment and perifoveal thickness

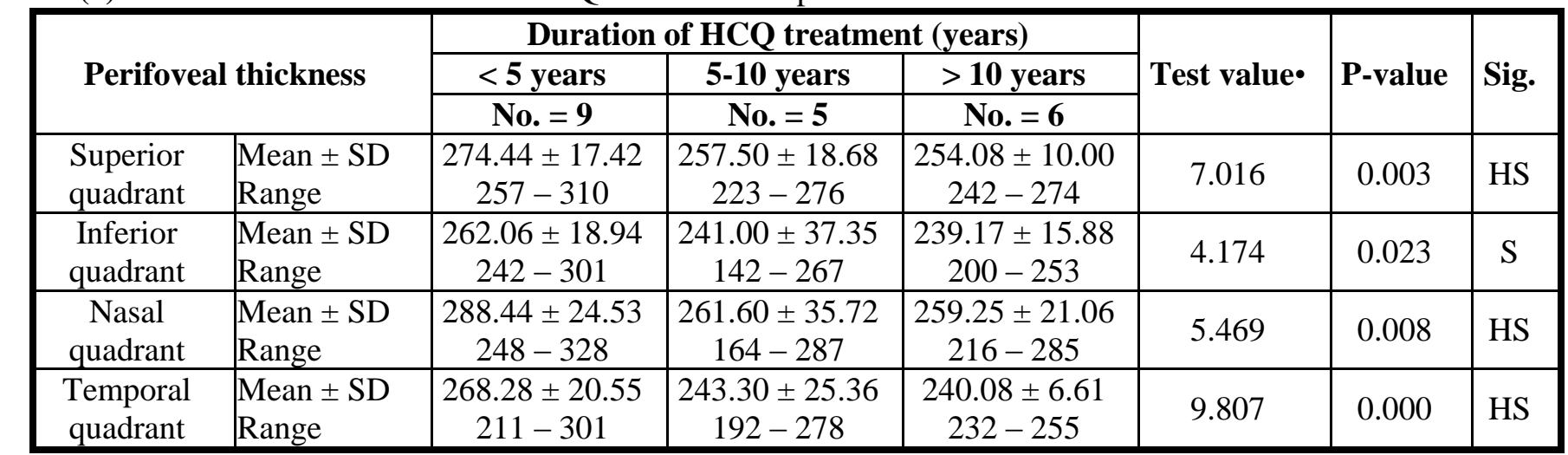

$\bullet$ One Way ANOVA

Table (7) showed that there was highly statistically significant difference concerning the duration of HCQ treatment and its effect on perifoveal thickness in all quadrants except in inferior quadrant there was statistically significant difference.

\section{DISCUSSION}

RA is a systemic inflammatory disease associated with a number of extra-articular organ manifestations. Shama et al. ${ }^{(3)}$ found that most common ocular diagnosis in cases of RA was dry eye ( $94 \%)$, which is similar to our study finding. However, Tayel $\boldsymbol{e t}$ al. ${ }^{(7)}$ in their study found that AAU (50\%) was most common ocular diagnosis followed by corneal involvement (20\%). They did not mention about dry eye status in their study. Also, Ausayakhun et al. ${ }^{\left({ }^{8}\right)}$ found that in cases of RA, dry eye was seen in $46 \%$ of cases. Zlatanović $\boldsymbol{e t}$ al. ${ }^{(9)}$ in their study found that most common ocular diagnosis in cases of RA was KCS (64\%). While, Ravibabu et al. ${ }^{(10)}$ reported that in RA cases, most common ocular diagnosis was dry eye $(40 \%)$ followed by episcleritis (25\%). In addition, Hassan et al. ${ }^{(11)}$ found that in RA cases, the most common ocular diagnosis was dry eye (39\%) followed by uveitis $(20 \%)$.

Antimalarials are widely used nowadays in treatment of RA, most commonly used are CQ and HCQ. Cautious screening for complications particularly retinopathy became much easier after introduction of SD-OCT as a screening procedure.

The patients in our two groups were mainly females, this could be explained by the fact that RA is much more prevalent in females rather than in males, females are two to three times more likely to develop RA more than males ${ }^{\mathbf{1 2})}$.

The exact mechanism of retinal toxicity is unknown, previous studies have implicated damage to outer retinal structures.
Duncker et al. ${ }^{(13)}$ in SD-OCT scans, showed early affection to outer retinal structures in the parafoveal and perifoveal regions.

Kellner et al. ${ }^{(\mathbf{1 4})}$ found that in patients with HCQ retinopathy, SD-OCT detected alterations of the photoreceptor layers in the form of loss of photoreceptor inner segments indicated by the reduced outer nuclear layer thickness and the interruption or absence of the photoreceptors at inner/outer segment junction. In our study there was no statistically significant difference between both groups according to CFT, but there was statistically highly significant difference between both groups concerning parafoveal and perifoveal thickness with $\mathrm{P}$ value 0.000 showing thinning in parafoveal and perifoveal areas in group 2 who were using HCQ, which indicate early detection of retinopathy as they had normal fundus.

Jonathan et al. ${ }^{(15)}$ stated that SD-OCT was capable of identifying cases of early retinal toxicity by measuring its thickness and that the retinal thinning and structural abnormalities that occur in cases of early toxicity can be more readily identified if measured at a specific landmark: $1.0 \mathrm{~mm}$ from the fovea. Moreover, the parafoveal thinning caused by HCQ that was observed in our study is matching with Sanati and Thomas ${ }^{(16)}$ who found that parafoveal retinal thickness and volume measurements might be early evidence of CQ toxicity. Besides, OCT measurements as a part of CQ toxicity screening may be useful in early detection of CQ maculopathy. 

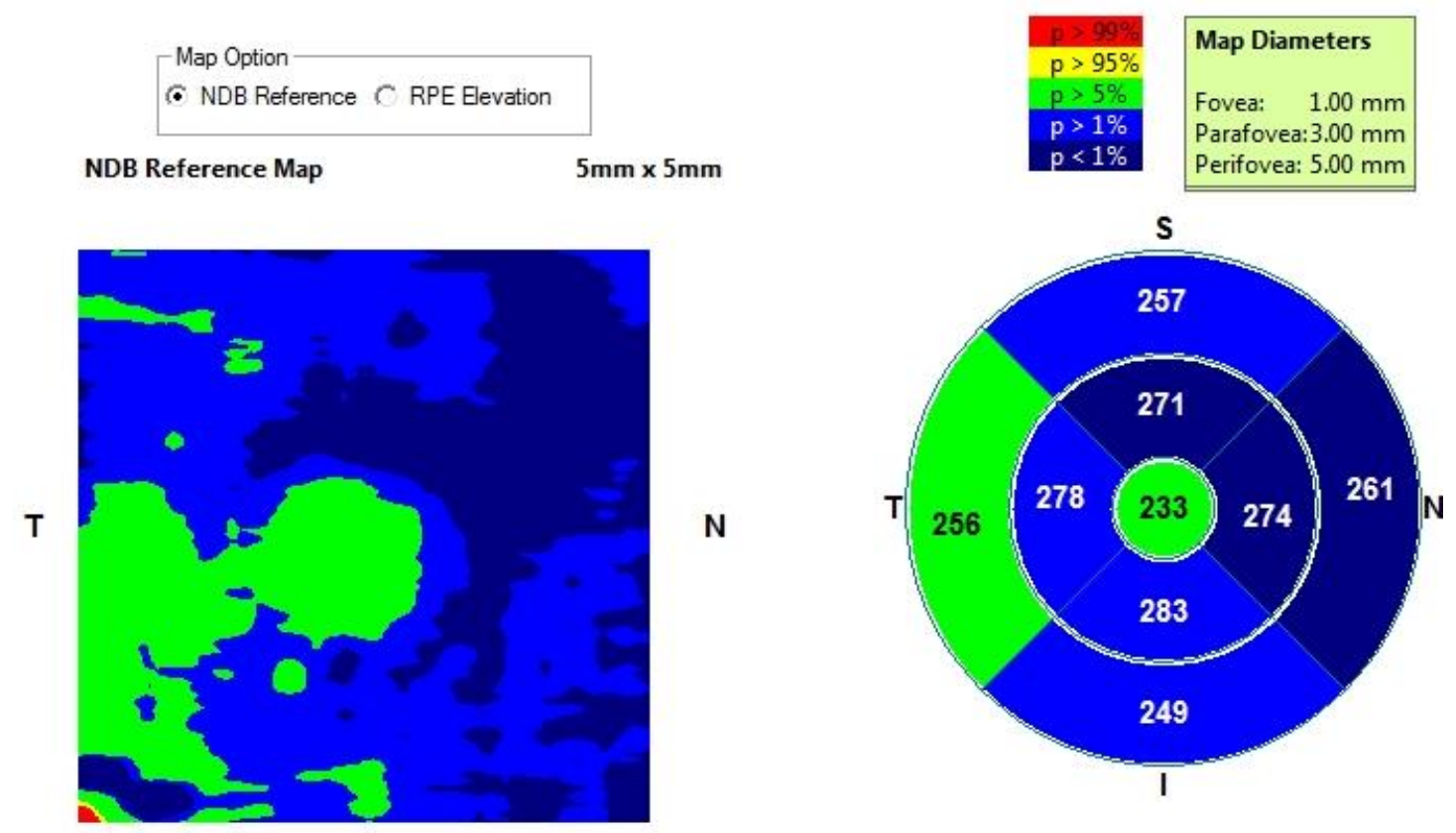

Figure (4): Map diameters from a patient in the group 2 showing parafoveal and perifoveal thinning.

Michel et al. ${ }^{17)}$ using SD-OCT identified concentric perifoveal collapse with loss of outer retinal layers, including the junction between inner and outer photoreceptor segment in both HCQ and CQ toxicity. Sanita and Thomas ${ }^{(16)}$ published a case report of a patient with CQ toxicity showing that the fovea (central circle) was of normal thickness while the parafoveal (inner circle) and perifoveal (outer circle) were thinned mainly temporally and inferiorly. This is matching with our study, which included larger number of patients where the four parafoveal quadrants were almost similarly affected with the temporal quadrant most frequently affected. Also, the perifoveal quadrants were similarly affected with the inferior quadrant most frequently affected with no significant thinning in central fovea.

Stepien et al. ${ }^{(18)}$ described a "preclinical" stage of HCQ toxicity where the photoreceptor IS/OS junction appeared "moth-eaten" due to preferential loss of cone photoreceptors. Marmor et al. ${ }^{\left({ }^{(19)}\right)}$ described the SD OCT findings as localized thinning of the retinal layers in the parafoveal region and confirmed early toxicity by loss of the inner/outer segment line. However, this wasn't not noticed in our study where IS/OS segment was interrupted in four patients only from group 2 compared to two patients from group 1 ( $\mathrm{P}$ value was not significant 0.375 ).

The risk factors for retinal toxicity by chloroquine are daily dose greater than $250 \mathrm{mg}$ / day or the cumulative dose greater than 300 grams ${ }^{(20)}$. Patients with duration of treatment greater than 5 years are liable to suffer from congestive liver and / or kidney disease, obesity (due to overdose) and previous retinal disease specially age greater than 60 years ${ }^{(21)}$. Ruther $\boldsymbol{e t}$ al. ${ }^{(22)}$, stated that although the risk of retinal degeneration increases with the duration of treatment, recent findings showed that many patients may take CQ or HCQ for many years without problems, whereas few patients develop retinal photoreceptor dysfunction at very low cumulative doses. Micheal et al. (17), believed that one of the most important factors appears to be with daily intake that believed to be more significant than cumulative dosage. However, in our study all the patients were taking fixed dose of HCQ $200 \mathrm{mg}$ twice per day in rheumatology clinic. So, they had the same daily dose but differed only in cumulative dose according to duration of treatment. Marmor et al. ${ }^{(19)}$ stated that most reported cases of toxicity occurred in patients using the drug for more than 7 years or with a cumulative dose that exceeds $1000 \mathrm{~g}$ HCQ (or $460 \mathrm{~g} \mathrm{CQ}$ ). The number of reported cases of likely toxicity begins to increase sharply after approximately 5 years of use. A cumulative dose of $1000 \mathrm{~g} \mathrm{HCQ}$ is reached in 7 years with a typical daily dose of $400 \mathrm{mg}$, and a cumulative dose of $460 \mathrm{~g} \mathrm{CQ}$ is reached in 5 years with a typical daily dose of $250 \mathrm{mg}$. This is matching with our study as there was correlation between treatment duration and parafoveal and perifoveal thinning as there was statistically significant difference in parafoveal and perifoveal thickness but there was nearly no correlation between CFT and treatment duration ( $\mathrm{p}$ value 0.704 ) .

\section{CONCLUSION}

Ocular manifestations of RA vary and are mainly keratoconjunctivitis sicca, episcleritis, scleritis, peripheral ulcerative keratitis and retinal vasculitis. Early signs of HCQ retinopathy can be determined by SD-OCT. So, SD-OCT can be used by 
ophthalmologists as a screening tool of patients taking HCQ.

\section{REFERENCES}

1. Sahatçiu-Meka V, Rexhepi S, Manxhuka-Kërliu S et al. (2010): Extraarticular manifestation of seronegative and seropositive reumathoid arthritis Bosn. J Basic Med Sci., 10 (1): 27-31.

2. Sobrin L, Kim EC, Christen W et al. (2007): Infliximab therapy for the treatment of refractory ocular inflamatory disease. Arch Ophthalmol., 125 (7): 895900.

3. Shama PK, Karthik K (2015): A Study on Ocular Manifestations of Rheumatoid Arthritis in a Tertiary Care Hospital in South India. Indian Journal of Applied Research, 5 (9): 223-25.

4. Melles RB, Marmor MF (2014): The risk of toxic retinopathy in patients on long-term hydroxychloroquine therapy. JAMA Ophthalmol., 132: 1453-60.

5. Imran HY, Cathy Y (2018): Eye screening for patients taking hydroxychloroquine (Plaquenil®): Macular Society. https://www.macularsociety.org/ sites/default/files/resource/Hydroxychloroquine $\% 20-\%$ 20access.

6. Latasiewicz M, Gourier H, Yusuf IH et al. (2017): Hydroxychloroquine retinopathy: an emerging problem. Eye, 31: 972-6.

7. Tayel MY, Mohannad N, El Gerby AH (2015): Prevalence and pattern of ocular involvement in patients attending Alexandria university Rheumatology clinic: a pilotstudy. International Journal of Advanced Research, 3 (6): 153-158.

8. Ausayakhun S, Louthrenoo W, Aupapong S (2002): Ocular Diseases Patients with rheumatic Diseases. J Med Assoc Thai., 85: 855-862.

9. Zlatanović G, Veselinović D, Cekić S et al. (2010): Ocular manifestation of rheumatoid arthritis-different forms and frequency. Bosn J Basic Med Sci., 10 (4): 323-7.

10. Ravibabu G, Sailaja B, Prasanna Sundari G (2015): Ocular Involvement in Connective Tissue Disorders in a Tertiary Hospital. citeseerx.ist.psu.edu > viewdoc > download

11. Hassan KM, Manish SR, Syed A et al. (2016): Ocular manifestations ofrheumatic diseases: A hospital based study. Indian Journal of Clinical and Experimental Ophthalmology, 2 (3): 242-247.
12. Aletaha $D$, Neogi $T$, Silman AJ et al. (2010): Rheumatoid Arthritis Classification Criteria: an American College of Rheumatology/European League against Rheumatism collaborative initiative. Arthritis Rheum., 62: 2569-2581.

13. Duncker G, Schmiederer M, BredehornT (1995): Chloroquine-induced lipidosis in the retina: a functional and morphological study. Ophthalmologica, 209 (2): 79-83.

14. Kellner S, Weinitz S, Kellner U (2009): Spectral domain optical coherence tomography detects early stages of chloroquine retinopathy similar to multifocal electroretinography, fundus autofluorescence and nearinfrared autofluorescence. Br J Ophthalmol., 93: 14441447.

15. Jonathan B, Ilyse D, Shantan R et al. (2011): SpectralDomain Optical Coherence Tomography as a Screening Technique for Chloroquine and Hydroxychloroquine Retinal Toxicity. Ophthalmic Surgery, Lasers \& Imaging, 42 (6): 493-497.

16. Sanita K, Thomas K (2008): Optical coherence tomography in a patient with chloroquine-induced maculopathy. Indian J Ophthalmol., 56 (6): 511-513.

17. Michel M, Niamh B, Peter J et al. (2011): Retinal Toxicity Associated With Hydroxychloroquine and Chloroquine Risk Factors, Screening, and Progression Despite Cessation of Therapy. Arch Ophthalmol., 129 (1): 30-39.

18. Stepien KE, Han DP, Schell J et al. (2009): Spectraldomain optical coherence tomography and adaptive optics may detect hydroxychloroquine retinal toxicity before symptomatic vision loss. Trans Am Ophthalmol Soc., 107: 28-33.

19. Marmor MF, Kellner U, Lai TY et al. (2011): Revised recommendations on screening for chloroquine and hydroxychloroquine retinopathy. Ophthalmology, 118: 415-22.

20. Gouveia EB, Morales MSA, Gouveia GB et al. (2007): Ocular toxicity derived from 4aminoquinolone. Arq Bras Oftalmol., 70 (6): 1046-51.

21. Marmor MF, Carr RE, Easterbrook M et al. (2002): Recommendations on screening for chloroquine and hydroxychloroquine retinopathy: a report by the American Academy of Ophthalmology. Ophthalmology, 109: 1377-82.

22. Ruther K, Foerster J, Bernedt S et al. (2007): Choroquine/hydroxychloroquine: Variability of retinotoxic cumulative doses. Ophthalmology, 104: 875-9. 